Crisliane Boito

Universidade Federal do Rio Grande do Sul, UFRGS

E-mail: crisliane.boito@gmail.com

(D) https://orcid.org/0000-0003-2089-2897

Simone Santos de Albuquerque Universidade Federal do Rio Grande do Sul, UFRGS

E-mail: sialbuq@gmail.com

(D) https://orcid.org/0000-0002-8510-3134

Recebido em: 22/11/2017

Aprovado em: 27/08/2019

\section{Um retrato da Educação Infantil no/do Campo no Rio Grande do Sul}

\author{
Crisliane Boito \\ Simone Santos de Albuquerque
}

\section{Resumo}

A Educação Infantil e as infâncias do campo têm registrado em diferentes marcos regulatórios de nosso país direitos essenciais no que se refere ao atendimento das crianças em instituições educativas. No entanto, mesmo com a luta dos movimentos sociais do campo e da Educação Infantil, dados apontam a discrepância entre o número de crianças matriculadas na etapa no contexto rural e urbano brasileiro (ROSEMBERG; ARTES, 2011). No Rio Grande do Sul, a demanda por creche e pré-escola, bem como as condições de oferta, foram questões estudadas pela pesquisa Caracterização do atendimento de crianças de 0 a 6 anos residentes em áreas rurais do Estado do Rio Grande do Sul/Brasil (2013-2016), a partir da imersão em dois contextos: um assentamento da Reforma Agrária e uma comunidade remanescente de quilombo. Neste artigo, apresentamos algumas proposições legais e norteadoras da Educação Infantil do Campo. Questionamos a relevância das pesquisas para mudanças reais às crianças do campo brasileiras e indicamos que a escola no campo é fundamental para a socialização das crianças, sendo necessário, no entanto, um trabalho pedagógico articulado com as especificidades culturais do contexto em que está inserida.

Palavras-chave: Educação Infantil. Educação do Campo. Oferta educacional. 
Abstract

Keywords:

Early childhood education.

Countryside

Education.

Educational

offering.

\section{Resumen}

Palabras-clave:

Educación

Infantil.

Educación del

campo. Oferta

educativa
A portrait of the early childhood education in/from the countryside in Rio Grande do Sul

The early childhood education and the countryside childhoods have been registering, by different regulations in our country, essential rights to the assistance of children in educational institutions. Although even with the countryside social movements and the early childhood education movements struggle, results pointed discrepancy between the number of children enrolled in the rural and urban brazilian contexts (ROSEMBERG;ARTES, 2011). In Rio Grande do Sul, the demand for nursery and preschool, as well as the offer conditions, were studied by the research "Description of the assistance for children from 0 to 6 years old, citizens in country areas on the fields in Brazil" (2013-2016) from the immersion in two contexts: assentamento da Reforma Agrária (a group of country workers that lives from farm work) and a reminescent community from a quilombo (community built by African American descendants). In this article we present some legal and guiding propositions of countryside early childhood education. We question the research relevance for true change to the brazilian countryside children, and indicate that the school in the countryside is fundamental for the children socialization. However, the pedagogical work must be articulated with the cultural specificities of the context it is in..

\section{Un retrato de la Educación Infantil en/ del campo en Rio Grande do} Sul

La Educación Infantil y las infancias del campo tienen registrado en diferentes marcos de regulación de nuestro país derechos esenciales en lo que se refiere al atendimiento de los niños en instituciones de educación. Sin embargo, mismo con la lucha de los movimientos sociales del campo y de la Educación Infantil, dados presentados por la investigación "Caracterización del atendimiento de niños de 0 a 6 años moradores en áreas rurales en Brasil" (2012) presentan la discrepancia entre el número de niños matriculados en la etapa en contexto rural y urbano brasileño. En Rio Grande do Sul, la demanda por guardería y preescolar, bien como las condiciones de oferta, fueran cuestiones estudiadas por la investigación "Caracterización del atendimiento de niños de 0 a 6 años moradores en áreas rurales en Brasil" (2013-2016), que realizó un estudio cuantitativo y cualitativo, a partir de una inmersión en dos contextos: asentamiento de la reforma agraria y una comunidad remaneciente de quilombo. En este artículo presentamos algunas propuestas legales y orientadoras de la educación rural en la primera infancia, cuestionamos la relevancia de la investigación para los cambios reales para los niños rurales brasileños y indicamos que la escuela en el campo es fundamental para la socialización de los niños, sendo necesitado, sin embargo un trabajo pedagógico articulado con las especificidades culturales del contexto en el que se inserta. 
Introdução

Eu não tinha este rosto de hoje, Assim calmo, assim triste, assim magro,

Nem o lábio amargo.

Eu não tinha estas mãos sem força,

Tão paradas e frias e mortas;

Eu não tinha este coração

Que nem se mostra

Eu não dei por esta mudança,

Tão simples, tão certa, tão fácil: - Em que espelho ficou perdida a minha face?(Cecília Meirelles)

Este artigo é fruto da mesa de debate Retratos da Educação Infantil do campo nas cinco regiões do Brasil, realizada no V Seminário Nacional de Educação Infantil do Campo, na Universidade Federal de Santa Catarina (UFSC), em outubro de 2016. Naquela oportunidade, buscamos apresentar alguns resultados da pesquisa Caracterização do atendimento de crianças de 0 a 6 anos residentes em áreas rurais do Estado do Rio Grande do Sul/Brasil (UFRGS, 2015), que desenvolvemos entre os anos de 2013 e 2016, com os seguintes objetivos:

a) analisar os dados relacionados à demanda e à oferta de Educação Infantil no/do Campo no âmbito do estado do Rio Grande do Sul, a partir do banco de dados da Pesquisa Nacional Caracterização do atendimento de crianças de 0 a 6 anos residentes em áreas rurais no Brasil (BRASIL; UFRGS, 2012a, 2012b);

b) analisar a oferta de atendimento em dois contextos de pesquisa - um assentamento da Reforma Agrária e uma comunidade remanescente de quilombo - no que se refere à qualidade da oferta da educação para as crianças de 0 a 6 anos residentes no campo.

Passado o evento, sentimo-nos ainda motivadas a 'retratar' um olhar de nossas vivências como pesquisadoras nos contextos de pesquisa e das discussões junto ao Grupo de Estudos de Educação Infantil e Infâncias (Gein) e ao Grupo de Pesquisa em Linguagens, Currículo e Cotidiano de bebês e crianças pequenas (Clique). No entanto, ao revisitar a organização dos dados e as problematizações compartilhadas naquele momento do seminário, sentimo-nos como Cecília Meirelles, que, ao olhar o seu próprio retrato, não se reconhece mais. 
Nos últimos anos, as mudanças políticas, os contingenciamentos e os cortes de verbas para a área da educação têm colocado diretamente em risco o direito das crianças brasileiras de 0 a 5 anos a um atendimento de qualidade em instituições públicas, sejam elas localizadas no campo ou na cidade. Assim, o tempo atual nos leva a pensar na urgência de provocar um debate para olhar a potência do passado, já que a Educação do Campo esteve na agenda política das últimas décadas; a complexidade do presente, pois vivemos em um tempo de constantes mudanças políticas e ideológicas; e a emergência do futuro, já que as crianças da Educação Infantil não esperam. É nessa etapa da vida e da educação em que também

[...] decidimos se amamos nossas crianças o bastante para não expulsá-las a seus próprios recursos, e tampouco arrancar de suas mãos a oportunidade de empreender alguma coisa nova e imprevista para nós, preparando-as em vez disso com antecedência para a tarefa de renovar um mundo comum. (ARENDT, 1972, p. 247).

Apoiadas nessa justificativa, organizamos o artigo em quatro seções. A primeira é intitulada A potência de um passado recente: legislação, documentos orientadores e emergência dos movimentos sociais. Nela, apresentamos de forma sintética algumas proposições legais e norteadoras da Educação Infantil do Campo, destacando o protagonismo histórico dos movimentos sociais e sindicais nessas articulações.

Na segunda seção, A complexidade do presente: a pesquisa como orientadora de ações políticas, problematizamos se as pesquisas realizadas na área têm possibilitado mudanças concretas na vida das crianças pequenas brasileiras residentes no campo. Nesta seção, apresentamos dados da Região Sul, especialmente do estado Rio Grande do Sul, relacionados às matrículas e aos projetos de construção ou reforma de Escolas de Educação Infantil do Campo.

$\mathrm{Na}$ terceira seção, A emergência da Educação Infantil do Campo: o futuro das crianças é o hoje, trazemos dados qualitativos de nossa imersão em dois contextos de pesquisa no estado do Rio Grande do Sul: um assentamento da Reforma Agrária e um quilombo. Nela, o destaque é dado à necessidade de que a oferta de vagas para a Educação Infantil do campo tenha qualidade, levando em conta as especificidades culturais e sociais de cada contexto.

Por fim, na última seção, Algumas considerações finais, resgatamos os pontos principais sobre as reflexões e os apontamentos expostos no decorrer do texto. 
A potência de um passado recente: legislação, documentos orientadores e emergência dos movimentos sociais e sindicais

No Brasil, nas últimas décadas, tem sido marcante a mobilização em defesa da Educação Infantil no/do Campo. Nesse sentido, consideramos fundamental destacar o protagonismo dos movimentos sociais e sindicais - em especial do movimento das mulheres trabalhadoras rurais, dos movimentos em defesa da Educação Infantil e dos movimentos vinculados à terra. Para Caldart (2008, p. 71-72):

\begin{abstract}
A Educação do Campo nasceu como mobilização/pressão de movimentos sociais por uma política educacional para comunidades camponesas: nasceu da combinação das lutas do sem-terra, pela implantação de escolas públicas nas áreas de reforma agrária, com as lutas de resistência de inúmeras organizações e comunidades camponesas para não perder suas escolas, suas experiências de educação, suas comunidades, seu território, sua identidade [...] A Educação do Campo ao nascer lutando por direitos coletivos, que dizem respeito à esfera do público, nasceu afirmando que não se trata de qualquer política pública: o debate é de forma, conteúdo e sujeitos envolvidos. A Educação do Campo nasceu também como crítica a uma educação pensada em si mesma ou em abstrato; seus sujeitos lutaram desde o começo para que o debate pedagógico se colasse à sua realidade, de relações sociais concretas, de vida acontecendo em sua necessária complexidade.
\end{abstract}

Com o passar do tempo, de alguma forma, a luta dos movimentos sociais e sindicais teve ressonância no Ministério da Educação (MEC), principalmente pelas ações desenvolvidas pela Secretaria de Educação Continuada, Alfabetização, Diversidade e Inclusão $\left(\right.$ Secadi) ${ }^{1}$. Nesse sentido, importantes proposições, bases legais e documentos orientadores foram elaborados, visando à defesa de uma educação respeitosa aos modos de vida das populações residentes em áreas rurais.

Nessa perspectiva, a Resolução $n^{0} 1$, de 3 de abril de 2002, editada pela Câmara de Educação Básica (CEB) do Conselho Nacional de Educação (CNE), que estabelece as Diretrizes Operacionais para a Educação do Campo (BRASIL, 2002), foi um marco na legislação nacional. Essas Diretrizes instituíram alguns princípios que visam à adequação do projeto institucional das Escolas do Campo às Diretrizes Curriculares Nacionais (DCN), buscando uma articulação da cultura, nestes termos:

Art. $2^{\circ} .[\ldots]$

Parágrafo único. A identidade da Escola do Campo é definida pela sua vinculação às questões inerentes à sua realidade, ancorando-se na temporalidade e saberes próprios dos estudantes, na memória coletiva que sinaliza futuros, na rede de ciência e tecnologia disponível na sociedade e nos movimentos sociais em defesa de projetos que associem as soluções exigidas por essas questões à qualidade social da vida coletiva no país.

[...]

Art. $5^{\circ}$ As propostas pedagógicas das Escolas do Campo, respeitadas as diferenças e $\mathrm{o}$ direito à igualdade e cumprindo imediata e plenamente o estabelecido nos artigos 
23, 26 e 28 da Lei 9.394/1996 [Lei de Diretrizes e Bases da Educação Nacional LDBEN], contemplarão a diversidade do campo em todos os seus aspectos: sociais, culturais, políticos, econômicos, de gênero, geração e etnia.

Parágrafo único. Para observância do estabelecido neste artigo, as propostas pedagógicas das Escolas do Campo, elaboradas no âmbito da autonomia dessas instituições, serão desenvolvidas e avaliadas sob a orientação das Diretrizes Curriculares Nacionais para a Educação Básica e a Educação Profissional de Nível Técnico. (BRASIL, 2002).

Mais tarde, essa disposição alinhou-se às Diretrizes Complementares de Educação do Campo, Resolução CNE/CEB n 2, de 28 de abril de 2008 (BRASIL, 2008), intensificando as discussões acerca da especificidade da população do campo. Nessas Diretrizes Complementares, ficaram estabelecidas como populações rurais os agricultores familiares, os extrativistas, os pescadores artesanais, os ribeirinhos, os assentados e os acampados da Reforma Agrária, os quilombolas, os caiçaras, os povos da floresta, entre outros. Também foi destacada a necessidade de oferecer condições materiais para a implementação das propostas pedagógicas, destacando-se a questão do transporte intra e extracampo, devido à complexidade e ao enfrentamento necessário dessa questão para a Educação no/do Campo.

Outro marco que consideramos importante destacar é a Resolução CNE/CEB no 5 , de 17 de dezembro de 2009 (BRASIL, 2009a), responsável pela revisão das Diretrizes Curriculares Nacionais para a Educação Infantil (DCNEI). Esta, por sua vez, além de evidenciar a concepção de criança e de currículo da etapa, foi a primeira regulamentação nacional que articulou a Educação do Campo à Educação Infantil no que se refere à discussão curricular. No $3^{\circ}$ parágrafo do Art. $8^{\circ}$ das DCNEI, foram estabelecidas indicações para práticas pedagógicas com as crianças residentes em áreas rurais e desenhadas as especificidades da Educação Infantil para crianças do campo, de modo a garantir igualdade com respeito à diversidade.

I-Reconhecer os modos próprios de vida no campo como fundamentos para a constituição da identidade das crianças moradoras em territórios rurais;

II-Ter vinculação inerente à realidade dessas populações, suas culturas, tradições e identidades, assim como as práticas ambientalmente sustentáveis;

III-Flexibilizar, se necessário, calendário, rotinas e atividades respeitando as diferenças quanto à atividade econômica dessas populações;

IV-Valorizar e evidenciar os saberes e o papel dessas populações na produção de conhecimentos sobre o mundo e sobre o ambiente natural;

V-Prever a oferta de brinquedos e equipamentos que respeitem as características ambientais e socioculturais da comunidade. (BRASIL, 2009a).

Dando sequência a essas proposições legais, foi elaborado, no ano de 2010, o documento Orientações curriculares para a Educação Infantil do Campo (SILVA; PASUCH, 2010), que buscou, de forma mais específica, definir princípios e práticas pedagógicas para a escola de Educação Infantil no/do Campo. Nesse texto, as autoras tecem os fios que ligam a Educação do Campo e a Educação Infantil, apontando reflexões necessárias e possibilidades 
para a construção de práticas pedagógicas que contemplem as especificidades das crianças do campo.

Nesta breve síntese das proposições legais e orientadoras vinculadas à Educação Infantil no/do campo, é importante assinalar que foi a partir do debate havido entre o Grupo de Trabalho que contribuiu para a produção do texto orientador acima citado e das discussões realizadas no I Seminário Nacional de Educação Infantil do Campo (2010) que se reconheceu ainda mais a necessidade de obter dados sobre a educação das crianças de 0 a 5 anos que residem no campo brasileiro. Assim, a partir de uma cooperação técnica entre o MEC e a Universidade Federal do Rio Grande do Sul (UFRGS), foi iniciada a Pesquisa Nacional Caracterização das Práticas Educativas com crianças de 0 a 6 anos residentes em áreas rurais (BRASIL; UFRGS, 2012a, 2012b), estabelecendo uma grande rede de diálogo sobre a realidade das cinco regiões do país, por meio de estudos quantitativos e qualitativos.

Embora acreditemos que, nas últimas décadas, construímos legislações, documentos orientadores e movimentos em prol de uma Educação Infantil do/no Campo para as crianças pequenas, sabemos que estes princípios não são assegurados na prática pedagógica. Há muitos desafios a serem enfrentados pelas Escolas no Campo para que as crianças tenham acesso à educação com qualidade.

\section{A complexidade do presente: a pesquisa como orientadora de ações políticas}

Creio ainda que podemos acreditar que a finalidade do conhecimento é também, e principalmente, a de buscar, criar, consolidar, desmontar, rebuscar e recriar as respostas às verdadeiras necessidades humanas. Podemos mesmo lembrar a ideia de Berthold Brecht, ontem e hoje partilhada por tantas outras pessoas: a finalidade da ciência é aliviar a miséria da condição humana. Mais ainda: a finalidade de todo o conhecimento é o partilhar na construção da felicidade de todas e todos os seres vivos deste Planeta Terra. (BRANDÃO, 2014, p. 13).

A epígrafe de Brandão nos provoca a pensar se, como e em que amplitude as pesquisas e as articulações dos movimentos sociais, sindicais e acadêmicos têm fomentado ações diretas nos contextos de vida das populações do campo. O conhecimento produzido na área da Educação Infantil no/do campo nos últimos anos está sendo compartilhado de modo a construir a felicidade das pessoas e das crianças moradoras do campo? Acreditamos que este é o nosso desafio, contribuir com a análise de dados para subsidiar ações políticas concretas para as crianças pequenas do campo. 
Neste artigo, as fontes utilizadas para análise sobre a oferta de Educação Infantil para crianças de 0 a 5 anos residentes no campo são: a Ação $2^{2}$ da Pesquisa Nacional Caracterização das práticas educativas com crianças de 0 a 6 anos residentes em área rural (BRASIL; UFRGS, 2012a, 2012b), que utilizou microdados do Censo Demográfico (Instituto Brasileiro de Geografia e Estatística - IBGE) e do Censo Escolar (Instituto Nacional de Pesquisas em Educação Anísio Teixeira - Inep), ambos do ano de 2010; dados produzidos no acesso do Laboratório de Dados Educacionais da Universidade Federal do Paraná (UFPR) com microdados do Inep de 2016; e dados do Sistema Integrado de Monitoramento e Controle (Simec) atualizados em julho de $2017 .^{3}$

As Tabelas 1, 2 e 3, apresentadas na sequência, sintetizam dados referentes à Região Sul do Brasil. Na tabela 1, é possível observar, a partir de dados do Inep 2010, o grande número de municípios que não ofertavam Educação Infantil na região, especialmente no campo.

Tabela 1 - Quantidade de municípios que não possuem matrículas em Educação Infantil, conforme localização das escolas (rural e urbana) -2010

\begin{tabular}{|c|c|c|c|c|c|c|c|c|c|}
\hline \multirow{3}{*}{ Estado } & \multirow{3}{*}{$\begin{array}{c}\text { Número de } \\
\text { municípios } \\
\text { por Estado e } \\
\text { Região Sul }\end{array}$} & \multicolumn{4}{|c|}{ Creche } & \multicolumn{4}{|c|}{ Pré-escola } \\
\hline & & \multicolumn{2}{|c|}{ Parcial } & \multicolumn{2}{|c|}{ Integral } & \multicolumn{2}{|c|}{ Parcial } & \multicolumn{2}{|c|}{ Integral } \\
\hline & & Urbana & Rural & Urbana & Rural & Urbana & Rural & Urbana & Rural \\
\hline RS & 497 & 353 & 487 & 194 & 467 & 53 & 165 & 299 & 470 \\
\hline $\mathrm{SC}$ & 295 & 142 & 244 & 82 & 227 & 13 & 70 & 191 & 251 \\
\hline PR & 399 & 247 & 387 & 36 & 355 & 25 & 245 & 190 & 372 \\
\hline $\begin{array}{l}\text { Região } \\
\text { Sul }\end{array}$ & 1191 & 742 & 1.118 & 312 & 1.049 & 91 & 480 & 680 & 1.093 \\
\hline
\end{tabular}

Nota: As informações referem-se às matrículas da rede pública municipal e estadual. Fonte: BRASIL e UFRGS (2012a, 2012b).

Ao tomar para análise o Rio Grande do Sul, foco deste artigo, percebemos que naquele período dos 497 municípios do estado, poucos eram os que possuíam matrículas em escolas na área rural. Os percentuais de municípios gaúchos com oferta de matrículas para as crianças pequenas do campo eram de apenas 2,02\%, em creche parcial, 6,04\% em creche integral, $66,80 \%$ em pré-escola parcial e $5,42 \%$ em pré-escola integral.

Nesta mesma perspectiva de discrepância entre o urbano e rural, o total de matrículas das crianças pequenas de 0 a 5 anos e 11 meses também era significativa em todos os estados da Região Sul, conforme tabela abaixo: 
Tabela 2 - Total de matrículas em Educação Infantil, conforme a localização das escolas - 2010

\begin{tabular}{crrrrrrrr}
\hline \multirow{2}{*}{$\begin{array}{c}\text { Estado e } \\
\text { Região Sul }\end{array}$} & \multicolumn{2}{c}{ Creche parcial } & \multicolumn{2}{c}{ Creche integral } & \multicolumn{2}{c}{ Pré-escola parcial } & \multicolumn{2}{c}{ Pré-escola integral } \\
\cline { 2 - 8 } & Urbana & Rural & Urbana & Rural & Urbana & Rural & Urbana & Rural \\
\hline RS & 7.038 & 65 & 53.526 & 1.081 & 80.461 & 12.631 & 24.915 & 838 \\
SC & 13.785 & 1.229 & 70.805 & 3.300 & 81.997 & 14.940 & 29.652 & 1.568 \\
PR & 8.026 & 192 & 86.363 & 1.332 & 85.246 & 5.845 & 40.311 & 841 \\
Região Sul & 28.849 & 1.486 & 210.694 & 5.713 & 247.704 & 33.416 & 94.878 & 3.247 \\
\hline
\end{tabular}

Nota: As informações referem-se às matrículas da rede pública municipal e estadual. Fonte: BRASIL e UFRGS (2012a, 2012b).

A partir dos dados do Inep (2010), é possível verificar que o estado do Rio Grande do Sul foi o que apresentou o menor número de matrículas em Educação Infantil rural, tendo como única exceção a etapa da pré-escola parcial, em que o estado do Paraná possuía número de matrículas inferior. Esta constatação referente ao aumento do atendimento na pré-escola do campo no Rio Grande do Sul possibilita que problematizemos em que medida isso aconteceu.

Durante a pesquisa in loco no estado, observamos que, majoritariamente, tal atendimento dava-se em turmas de pré-escola em instituições de Ensino Fundamental, com experiências que desconsideravam as especificidades da Educação Infantil, sendo os tempos, os espaços e materiais pensados a partir da lógica daquela etapa de ensino.

A tabela a seguir foi elaborada a partir dos dados do INEP 2016, disponibilizados na Plataforma do Laboratório de Dados Educacionais/ UFPR, e aponta significativa evolução do número de matrículas nos últimos anos em todos os estados da Região Sul ${ }^{4}$.

Tabela 3 - Total de matrículas em Educação Infantil, conforme a localização das escolas - 2016

\begin{tabular}{crrrrrrrr}
\hline \multirow{2}{*}{$\begin{array}{c}\text { Estado e } \\
\text { Região Sul }\end{array}$} & \multicolumn{2}{c}{ Creche parcial } & \multicolumn{2}{c}{ Creche integral } & \multicolumn{2}{c}{ Pré-escola parcial } & \multicolumn{2}{c}{ Pré-escola integral } \\
\cline { 2 - 9 } & Urbana & Rural & Urbana & Rural & Urbana & Rural & Urbana & Rural \\
\hline RS & 35.450 & 337 & 141.794 & 1.805 & 149.473 & 17.499 & 63.181 & 1.823 \\
SC & 37.886 & 1.106 & 119.490 & 4.927 & 118.297 & 12.299 & 42.081 & 2.455 \\
PR & 47.816 & 297 & 162.095 & 1.488 & 162.271 & 11.405 & 58.255 & 609 \\
Região Sul & 121.152 & 1.740 & 423.379 & 8.220 & 430.041 & 41.203 & 163.517 & 4.887 \\
\hline
\end{tabular}

Fonte: Elaborada pelas autoras a partir do Banco de Dados do laboratório de Dados Educacionais/UFPR.

Analisando-se as Tabelas 2 e 3, é possível observar que, entre os dados de 2010 e de 2016, houve um avanço significativo no percentual de matrículas de crianças em pré-escolas na Região Sul, tanto no âmbito rural quanto no urbano. Embora os dados das tabelas expressem um crescimento quantitativo importante no que se refere às matrículas, não podemos afirmar 
quais as condições desta oferta. Estas crianças estão agrupadas em classes multisseriadas? Quais as condições dos espaços e materiais ofertados nas turmas de pré-escola?

O que é possível afirmar é que o campo sofre a desigualdade de acesso a políticas públicas estruturais, como saneamento, saúde e, principalmente, educação. Assim, ao tempo em que destacamos a relevância da legislação referente à obrigatoriedade de matrícula, já que impulsionou a oferta por parte do estado, enfatizamos que a oferta deve estar aliada à qualidade.

Os fatores que têm intensificado a oferta e a demanda, principalmente da pré-escola, estão implicados em dois aspectos principais: a alteração da Constituição Federal de 1988 $(\mathrm{CF} / 1988)$ no que se refere à escolaridade obrigatória dos 4 aos 17 anos; e a busca por cumprir as metas previstas no Plano Nacional de Educação (PNE), Lei n ${ }^{\circ} 13.005$, de 25 de junho de 2014 (BRASIL, 2014), com a universalização de atendimento, até 2016, para as crianças da pré-escola (4 e 5 anos) e o atendimento de no mínimo 50\% das crianças de até 3 anos, antes do final da vigência do Plano (Meta 1).

Nesse sentido, diferentes iniciativas para a ampliação da oferta foram tomadas pelos governos federal e municipal, dentre as quais podemos destacar a ampliação de turmas de préescola em escolas de Ensino Fundamental, a diminuição da oferta para crianças na faixa entre 0 e 3 anos de idade em turno integral para a ampliação das matrículas das crianças de 4 e 5 anos em turno parcial; a construção de novas escolas através do convênio com o Programa Nacional de Reestruturação e Aquisição de Equipamentos para a Rede Escolar Pública de Educação Infantil (Proinfância), entre outros arranjos.

No que tange à ampliação de matrículas no campo no Rio Grande do Sul, é possível observar a disparidade na sua evolução, em dois aspectos principais: a) a localização, uma vez que, no período de 2010 a 2016, a etapa da pré-escola parcial teve crescimento de $86 \%$ em áreas urbanas, ao passo que a expansão na área rural foi de $39 \%$; b) a faixa etária, embora as matrículas rurais em creche parcial tenham tido um aumento de $418 \%$, o atendimento passou de apenas 65 para 337 matrículas, reafirmando a invisibilidade dos bebês e crianças bem pequenas residentes no campo gaúcho (ROSEMBERG, 2012; RIO GRANDE DO SUL, 2016).

É interessante evidenciar que, no Rio Grande do Sul, o Tribunal de Contas do Estado (TCE/RS) monitora a oferta de vagas de Educação Infantil nos municípios desde o ano de 2008 e divulga em radiografias anuais a análise da etapa, com vistas ao PNE. No que diz respeito à oferta de vagas para crianças pequenas do campo, o TCE/RS, a partir da divulgação 
dos dados da Pesquisa Nacional, tem incorporado em seus relatórios dados referentes à renda mensal per capita e os índices de pobreza relativos à população rural e urbana na faixa etária entre 0 e 5 anos. Consideramos que esta inclusão é uma ação política provocada pela pesquisa.

Outra ação relacionada à pesquisa e às articulações entre o MEC, o Plano Nacional de Educação do Campo e a Secadi foi a implantação do Programa Nacional de Educação do Campo (Pronacampo) no ano de 2013. Este programa conta com quatro importantes eixos, entre os quais o último é nomeado 'Estrutura física e tecnológica' e conta com o subeixo 'Construção de escolas', destacando o "espaço para a Educação Infantill, que tem como objetivo:

Disponibilizar apoio técnico e financeiro para a melhoria das condições de infraestrutura das escolas, atendendo as necessidades da Educação do Campo e quilombola, para a oferta de atividades pedagógicas, profissionalizantes, esportivas, culturais, de horta escolar, alojamentos para professores e educandos e espaço para a educação infantil. (BRASIL, 2017, grifos nossos).

A ação 4 do Pronacampo prevê a construção de escolas com projetos específicos e padronizados para a Educação do Campo. Esse objetivo foi reforçado em 2014, pelo Grupo de Trabalho Interinstitucional (GTI) para Educação Infantil do Campo, no documento Educação Infantil do campo: Proposta para a expansão da política, que recomendou que fosse promovido "[...] o desenvolvimento de um plano de construção de escolas infantis rurais, considerando os critérios e especificidades escolares" (BRASIL, 2014, p. 30).

No entanto, a partir de dados disponibilizados pelo Simec sobre o andamento de projetos relacionados a construções e/ou reformas de instituições de Educação Infantil no Campo em nível nacional, no período de 2007 a 2017, podemos observar que ainda são tímidos os avanços nesse sentido, conforme apresenta tabela 4:

Tabela 4 - Projetos de Escolas de Educação Infantil do Campo por região do país

\begin{tabular}{ccc}
\hline Região do país & Número de projetos & Porcentagem \\
\hline Sul & 7 & $4,22 \%$ \\
Sudeste & 25 & $15,06 \%$ \\
\hline Centro-Oeste & 6 & $3,61 \%$ \\
\hline Nordeste & 70 & $42,17 \%$ \\
\hline Norte & 58 & $34,94 \%$ \\
Total & $\mathbf{1 6 6}$ & $\mathbf{1 0 0 \%}$ \\
\hline Fonte: elaborada pelas autoras a partir de dados do Simec $(2017)$.
\end{tabular}


Os baixos percentuais de projetos em todas as regiões do país, com destaque ainda mais negativo às Regiões Sul e Centro-Oeste, revelam a complexidade da questão. No que se refere à Região Sul, os projetos estão distribuídos e desenvolvidos conforme Tabela 5, a seguir:

Tabela 5 - Projetos de Escolas de Educação Infantil na Região Sul do Brasil

\begin{tabular}{|c|c|c|c|c|}
\hline Estado & $\begin{array}{c}\text { Número de } \\
\text { projetos }\end{array}$ & Programa & Tipo de Obra & Fase da obra \\
\hline Rio Grande do Sul & 1 & Proinfância & Tipo B & Concluída \\
\hline Santa Catarina & 4 & $\begin{array}{l}\text { Proinfância } \\
\text { PAR } \\
\text { PAR } \\
\text { Proinfância }\end{array}$ & $\begin{array}{l}\text { Tipo C } \\
\text { Projeto } 2 \text { Convencional } \\
\text { Ampliação } \\
\text { Projeto } 2 \text { Convencional }\end{array}$ & $\begin{array}{r}\text { Concluída } \\
\text { Concluída } \\
\text { Concluída } \\
\text { Em execução }\end{array}$ \\
\hline Paraná & 2 & $\begin{array}{l}\text { Cobertura } \\
\text { PAR }\end{array}$ & $\begin{array}{l}\text { Projeto FNDE - cobertura de } \\
\text { quadra } \\
\text { Projeto elaborado pelo } \\
\text { proponente }\end{array}$ & $\begin{array}{l}\text { Paralisada } \\
\text { Cancelada }\end{array}$ \\
\hline
\end{tabular}

Fonte: elaborada pelas autoras a partir de dados do Simec (2017).

A partir dos dados acima, podemos observar o quanto a movimentação de ações políticas para as crianças pequenas do campo é lenta, sendo o Programa Nacional de Reestruturação e Aquisição de Equipamentos para a Rede Escolar Pública de Educação Infantil (Proinfância) uma iniciativa que não teve impacto na ampliação da oferta de Educação Infantil neste contexto. Especificamente a respeito do Proinfância no Rio Grande do Sul, novamente a desigualdade entre o rural e o urbano é expressiva: entre 2007 e 2015, foram concluídas 358 unidades de Educação Infantil no contexto urbano (643 contratos foram firmados) e 1 unidade concluída em contexto rural.

Relatórios do Projeto de Assessoria Técnico-Pedagógica (UFRGS, 2014) realizado em 157 municípios gaúchos (2012/2013) apontaram a necessidade de construção e ampliação de instituições de Educação Infantil no campo, com propostas que respeitem suas especificidades. Outro dado destacado nos Relatórios foi a demanda dos municípios para resolução da problemática do transporte público de crianças pequenas.

É possível afirmar a necessidade de os recursos públicos brasileiros serem igualmente distribuídos para todos, levando-se em consideração a localização e questões sociais, econômicas, raciais e geracionais, pois os dados até aqui apresentados demonstram que as crianças pequenas residentes em áreas rurais não foram contempladas com as novas escolas do Proinfância.

Mesmo diante dos dados e dos indicativos dos Relatórios de Assessoria apresentados, desde 2015 não há previsão de continuidade do Proinfância, apenas alguns encaminhamentos 
jurídicos para a finalização de obras inacabadas. Também não há nenhum novo programa específico para fomentar a ampliação de vagas para Educação Infantil urbana ou rural em nosso país. Nesse viés, corroboramos as preocupações de Albuquerque, Felipe e Corso (2017) quando destacam, com perplexidade, as ações do "novo', governo em relação a um rompimento como o compromisso legal de entender a Educação Infantil como um direito da criança e de sua família.

Preocupa-nos o fato de que, com a redução de investimentos na educação, novamente as crianças pequenas do campo tenham negados seus direitos, o vai na contramão da história de conquistas das últimas décadas. Consideramos que, ao descartar cláusulas pétreas de nossa Constituição que estão vinculadas aos investimentos necessários à educação, estamos descartando também a possibilidade de desenvolvimento de uma geração, considerando que o tempo da infância, como veremos na próxima seção, é o hoje.

\section{A emergência da Educação Infantil do Campo: o futuro das crianças é o hoje}

Após contemplar, neste artigo, a potência do passado e a complexidade do presente, acreditamos que refletir sobre a emergência da Educação Infantil das crianças é essencial e coerente com a proposta que lançamos nesta escrita. Para tanto, nesta seção, nosso foco será a etapa qualitativa do estudo Caracterização do atendimento de crianças de 0 a 6 anos residentes em áreas rurais do Estado do Rio Grande do Sul/Brasil (UFRGS, 2015) em que realizamos imersões em dois contextos do campo: um assentamento de Reforma Agrária em Eldorado do Sul e um quilombo no município de Guaíba.

A pesquisa foi realizada no período de fevereiro de 2013 a março de 2016, com diferentes imersões nos contextos pesquisados, sendo adotadas como estratégias metodológicas: a) observação participante; b) análise de documentos; c) escrita de diário de campo; d) entrevistas com representante do movimento social, gestores da instituição de Educação Infantil, famílias das crianças e, por fim, com as próprias crianças.

De início, queremos apontar que as imersões num contexto e noutro mostraram culturas, infầncias e perspectivas muito distintas. No contexto do assentamento Integração Gaúcha, o direito à matrícula das crianças de 0 a 5 anos em uma escola de Educação Infantil próxima à residência dessas crianças e de suas famílias é realidade e oportunidade de todos(as), subsidiada pelo poder público, especialmente a partir da articulação do movimento de mulheres assentadas. Já na comunidade Manuel Barbosa, remanescente de quilombo, a oferta de creche é inexistente; e a de pré-escola, limitada ao período parcial, sendo ofertada 
em uma escola de Ensino Fundamental, com a organização espacial e de mobiliário compartilhada com as crianças do primeiro ano.

Nas pesquisas de campo, observamos que, enquanto a oferta de vagas para as crianças desde a creche é relatada com satisfação pelas famílias do assentamento, como, por exemplo, "a creche é uma benção" (mãe de família entrevistada em 17/06/2014) e "a escola do assentamento é muito bom, é muito tudo de bom" (pai de família entrevistado em 30/05/2014), no quilombo, encontramos lamentações das famílias, tais como: “Eu queria trabalhar, mas não posso, porque não tenho onde deixar [os filhos], aqui perto não tem creche" (mãe de família entrevistada em 08/04/2015).

Reconhecemos, no quilombo, que a ausência de um lugar para deixar as crianças enquanto trabalham acaba por 'impedir' muitas mulheres de exercerem uma atividade rentável. Nesse sentido, entendemos que a oferta de vagas para Educação Infantil no campo precisa também ser encarada como uma política social que visa à igualdade entre homens e mulheres.

Nessa perspectiva, destacamos que o estudo realizado pelo Instituto Brasileiro de Geografia e Estatística (IBGE, 2014), denominado Estatística de Gênero: uma análise do Censo Demográfico 2010, afirma que uma política de ampliação da oferta de creches é transversal tanto às questões educacionais como também às questões de gênero, em especial no que se refere à autonomia e à inserção das mulheres no mercado de trabalho.

A impossibilidade de as mulheres/mães trabalharem restringe as finanças familiares e, assim, a qualidade de vida das famílias. No contexto do quilombo, de modo predominante, observamos um cenário de pobreza bastante preocupante, que compartilhamos a partir do registro feito no diário de campo, abaixo:

Foi numa tarde fria do inverno de 2015 que chegamos a uma das casas mais distante da escola. Local inacessível para chegar com transporte e, assim, precisamos caminhar em torno de $1 \mathrm{~km}$ em um trajeto com muito barro, devido às chuvas! Fazer pesquisa no contexto de campo tem dessas coisas. Da cerca longe onde batemos palmas, fomos convidadas para entrar e sentamos junto de uma pequena mesa, em alguns bancos improvisados. A escuridão da casa, que não possuía energia, apenas a claridade do final do dia, ainda iluminava o ambiente, que tinha um cheiro de lenha queimada. Participaram da entrevista as três crianças, mãe, pai e avô. E o relato daquela família da situação de miséria em que viviam foi de extrema relevância para compreendermos as dificuldades vividas por muitos moradores daquela comunidade. Pai desempregado, avô doente, a mãe sem condições de trabalhar, pois não tinha como deixar os dois filhos menores de 3 anos. A renda da família é resultado de um auxílio-doença e do Bolsa-Família. O menino de 5 anos tem muita dificuldade de frequentar a escola em função da falta de transporte escolar gratuito e sem as condições financeiras para pagar as passagens. A dificuldade com a alimentação e saúde das crianças foi uma das preocupações apresentadas pelos 
adultos, bem como o desejo de buscarem melhores condições para a sustentabilidade da família. No entanto, naquele momento, o desemprego e a falta de creche lhes impunham aquela situação de extrema pobreza. (Diário de campo -8 de abril de 2015).

Nessa perspectiva, O TCE/RS apresentou os seguintes dados:

Em 2010, 17,90\% da população de 0 a 5 anos encontrava-se em situação de miséria. O maior índice de pobreza estava na zona rural, onde $30,67 \%$ das crianças de 0 a 5 anos pertenciam a famílias com rendimento nominal mensal domiciliar per capita de até R\$ 140. Na zona urbana, esse índice era de 15,89\%. O Censo Demográfico comprova que as famílias em situação de pobreza têm maiores números de filhos, tornando indispensável à ação do poder público no acesso à educação às crianças de 0 a 5 anos. (RIO GRANDE DO SUL, 2015, p. 11).

Nas duas comunidades pesquisadas, deparamo-nos com a necessidade das famílias por creches. No entanto, enquanto na comunidade do assentamento as mulheres, por meio de muita luta, conquistaram a escola de Educação Infantil, na comunidade quilombola, essa ainda é uma demanda emergente - neste caso, para homens e mulheres, já que também nos deparamos com um pai solteiro que cuida sozinho do filho desde o nascimento. Ele trabalha como pintor (esporadicamente), mas relatou ter dificuldades para arrumar emprego, em função de ter de cuidar do filho pequeno. Para ele, a creche é uma necessidade imediata, já que no quilombo não existe atendimento para os bebês. Nessa questão, destacamos que a legislação referente à obrigatoriedade da pré-escola aos 4 anos oportunizou no quilombo a ampliação de vagas para essa faixa etária em detrimento da oferta de vagas para as crianças de 0 a 3 anos.

No que se refere à lei da obrigatoriedade de matrícula na pré-escola, Lei ${ }^{\circ} 12.796$, de 4 de abril de 2013 (BRASIL, 2013a), em ambos os contextos pesquisados, ela foi considerada positiva pela maioria das famílias. Elas se declararam felizes com a proposta educativa e as atividades que a escola tem realizado, destacando o papel fundamental desta instituição na vida de seus filhos, para que eles "se tornem alguém na vida" e tenham um "futuro melhor", comparado ao de seus pais, que também viveram sua infância no campo e ainda sentem muitas dificuldades com contas e escrita, por exemplo, pois não tiveram a oportunidade de estudar.

Nesse sentido, pudemos observar uma relação entre a oferta e a demanda, isto é, o reconhecimento das experiências de Educação Infantil para as crianças do campo nas escolas oportuniza que as famílias e comunidades afirmem que a Educação Infantil tem como função principal o desenvolvimento, a socialização e a aprendizagem das crianças. Assim, essa experiência de escola implica a necessidade de ampliação da oferta, tanto para a creche 
quanto para a pré-escola, uma vez que a comunidade encontra na escola infantil um "lugar privilegiado" para a educação das crianças, buscando atendimento e o direito à vaga.

Outro aspecto destacado pelas famílias gaúchas na pesquisa foi a ampliação da escolarização na Educação Básica nos contextos familiares. As novas gerações estão tendo "mais oportunidades do que nós tivemos", como afirmou um representante de movimento social em entrevista realizada em 12/05/2014, referindo-se a oportunidades de estudo. Compreendemos que essa experiência de ampliação da escolarização tem consequências na estruturação da vida no campo, na busca por melhores condições de trabalho, no bem-estar da família e na ampliação dos bens de consumo.

Aliada a essa questão, especialmente no contexto do assentamento, as famílias frisaram a importância de as novas gerações reconhecerem a luta dos pais e da comunidade pelo território e por toda a infraestrutura conquistada. Fica evidenciada, desse modo, a necessidade de articulação no que se refere à cultura das crianças:

[...] professores e comunidade, fazer uma espécie de assessoria técnica na escola e voltar a questão para nossas raizes, mostrar de onde vem o alimento, reciclar, plantar. Esse é o nosso ambiente, daqui que a gente tira o nosso sustento, valorizar essa terra que a gente conquistou. Isso precisa aprofundar, esse trabalho é sempre isolado. Tinha que ser permanente [...]. (Representante de movimento social, entrevista realizada em 12/05/2014).

A essencialidade da formação continuada de professores no cotidiano da Escola do Campo também precisa ser refletida. Uma das professoras da escola localizada na comunidade quilombola relatou-nos em entrevistas a sua inserção na escola e a pesquisa que precisou fazer para entender "quem são esses tal de quilombola" (entrevista com professora realizada em 21/10/2016). A partir disso, aponta para a necessidade e a importância do reconhecimento dessa comunidade. Ela afirmou que, ao chegar à instituição e se deparar com essa realidade, que era novidade para ela, não conseguiu encontrar ajuda de suas colegas, que nada sabiam acerca desses sujeitos:

Quando cheguei aqui, a primeira coisa foi me informar. Porque, até então, não entendia o que era um quilombola. Perguntei para as colegas, ninguém soube me responder. Então, em primeiro lugar, fui entrar em uma internet e pesquisar um pouco sobre o assunto e, em segundo lugar, dei uma visitada na comunidade, para saber o que era e como é que funcionava e coisa e tal. (Entrevista com professora, realizada em 21/10/2016).

Diante do exposto anteriormente, é nítido o reconhecimento da necessidade de formação continuada e específica no que se refere aos sujeitos que pertencem a essa escola e a essa comunidade. A professora entrevistada reconhece a questão da formação para essa especificidade ao tecer uma crítica contundente contra o sistema positivo, que é aplicado aos 
Anos Iniciais do Ensino Fundamental dessa instituição. Segundo a docente, a proposta acarreta consequências e dificuldades, devido às práticas pedagógicas descontextualizadas, apontando para a necessidade de uma formação docente mais sólida:

Tu sabes que eles trabalham com o livro do positivo, né? Que veio 18 milhões do governo e coisa e tal. Só que assim, o livro é todo pronto, então o que acontece? Tem que fazer todo mundo andar na mesma linha, todo mundo na mesma página, no mesmo exercício. Se os professores escolheram isso, é porque na realidade eles nem devem saber o que estão escolhendo, creio eu. Eu acho que falta muita formação para esse povo, pois mesmo que aqui seja rural tem que ter uma faculdade, tem que ter curso, tem que abrir a cabeça, tem que ler, tem que fazer alguma coisa diferente e ver um mundo diferente. E é isso, né? Não se trabalha uma horta, não se trabalha uma coisa que seja do contexto da comunidade, uma planta, chás, ervas. Uma coisa que seria de utilidade para eles. Ou o cuidado com o meio ambiente, sei lá, hoje em dia tem tanta coisa. (Entrevista com professora, realizada em 21/10/2016).

Destacamos a formação de professores como um eixo fundamental para a construção de uma oferta de Educação Infantil do Campo na perspectiva da qualidade. No Brasil, a qualidade da Educação Infantil no contexto das políticas públicas nunca foi um tema simples, pois nosso processo histórico de algumas décadas de efetivação do direito à Educação Infantil como primeira etapa da Educação Básica é um tanto recente.

No que tange à qualidade, uma série de documentos brasileiros legitimam nossas referências para a etapa da Educação Infantil, como: Critérios de atendimento em creches que respeite os Direitos Fundamentais das crianças (1995, reeditado em 2009); Indicadores da qualidade na Educação Infantil (2009); Parâmetros básicos de infraestrutura para instituições de Educação Infantil (2006); Parâmetros nacionais de qualidade para a Educação Infantil (2006); Parâmetros nacionais de qualidade da Educação Infantil (2018).

Este último documento traduz uma orientação de nível nacional aos sistemas de ensino, com padrões de referência para a organização, gestão e funcionamento. Ele foi organizado em 8 áreas focais, 21 princípios e 239 parâmetros relacionados à qualidade da Educação Infantil brasileira, e já está alinhado às novas legislações e documentos orientadores, como a Base Nacional Comum Curricular (BNCC) (2017).

Assim, é possível afirmar que o Brasil já possui referenciais suficientes para orientar as práticas cotidianas de Educação Infantil, tanto em nível macro (sistemas municipais) como em nível micro (escolas), com parâmetros que apontam para a efetivação de uma Educação Infantil com qualidade. Mas também destacamos que nenhum dos documentos citados acima menciona a especificidade das crianças do campo, no entanto, como estudiosas da área, consideramos que podem ser considerados como uma perspectiva a partir de uma análise de contexto. Segundo as Orientações Curriculares para a Educação Infantil do Campo: 
Uma Educação Infantil do Campo de qualidade, para além dos indicadores gerais de qualidade da Educação Infantil, já construídos nacionalmente, necessita considerar novas questões, construindo um cenário de relações positivas da criança com suas origens e lugares de vida, consigo mesma e com o seu grupo de referência, valorizando suas experiências cotidianas. É nos Anos Iniciais que a criança constrói sua autoimagem, na relação com a imagem de seu grupo social e cultural e do lugar em que vive. (SILVA; PASUCH, 2010, p. 3).

Nesse sentido, é importante reconhecer a diversidade do campo, lembrando que os princípios da qualidade devem considerar as particularidades do contexto e da história dos sujeitos. Para nós, alguns aspectos são definidores da qualidade da oferta de Educação Infantil, seja no campo ou na cidade. Abaixo apresentamos alguns itens que consideramos fundamentais:

- construção da proposta pedagógica;

- relação construída com as famílias e a comunidade das crianças;

- formação permanente dos professores e profissionais que atuam na escola;

- infraestrutura da escola: espaço interno e externo, materiais (brinquedos, livros, jogos, etc.).

Os aspectos supracitados são, a nosso ver, extremamente relevantes no contexto de oferta, mas precisam ser redimensionados pelos sujeitos que fazem parte da comunidade escolar (crianças, famílias e professores), pois aqui a qualidade é entendida como um conceito “[...] dinâmico, contínuo, que requer revisões e nunca chega a um enunciado definitivo" (MOSS, 2002, p. 21).

Desse modo, evidenciamos a proposta pedagógica da escola como eixo fundamental de nossas análises sobre as condições de oferta e a qualidade da educação nos contextos pesquisados. Para nós, essa é a coluna vertebral de uma instituição escolar, uma vez que é a partir dela que emergem as práticas pedagógicas desenvolvidas junto das crianças. Consideramos fundamental que o Projeto Político-Pedagógico (PPP) das escolas de Educação Infantil do Campo tenha como eixo as legislações e os documentos orientadores apresentados na seção inicial deste trabalho, muito dos quais são desconhecidos pelos participantes da pesquisa, nos dois contextos pesquisados.

$\mathrm{Na}$ escola do assentamento, foi possível observar uma preocupação com as vivências e as culturas das crianças, os modos de viver no campo, a trajetória de suas famílias. Assim sendo, nesse contexto, a proposta evidenciava uma preocupação com o reconhecimento da cultura do campo e também com o diálogo com a cultura urbana, já que algumas crianças vinham da cidade para o campo. Na escola do quilombo, ao sermos informadas de que o PPP da unidade estava em construção, deduzimos que ocorreram algumas discussões e estudos 
para que a historicidade e a cultura das crianças pudessem ser incorporadas na proposta, mas que este era um esforço inicial e ainda não fazia parte do coletivo da escola.

Por meio de nossa experiência de pesquisa com as crianças, foi possível reconhecer a importância da participação delas na constituição da proposta da escola, bem como da possibilidade de opinarem sobre as experiências que vivenciam, no que se refere ao planejamento e à avaliação do projeto educativo. Assim, apontamos que o protagonismo e a identidade das crianças como sujeitos do campo precisam ser considerados na construção da proposta pedagógica e na constituição dos tempos e espaços no cotidiano escolar.

A elaboração da proposta pedagógica se apresenta como uma oportunidade singular para a construção de relacionamentos e trocas entre famílias e escola. Para isso, ambas precisam conhecer as lógicas de funcionamento, para que possam construir uma educação compartilhada da criança.

Os estudos realizados por Silva, Pasuch e Silva (2012) apontam para a necessidade de construir ações complementares entre creche/pré-escola e família, a fim de promover o desenvolvimento integral da criança. Segundo as autoras, é necessário um profundo “[...] conhecimento e respeito que se constrói na relação dinâmica e cotidiana entre as duas instituições, por meio de conversas e de ações planejadas para a promoção desta relação e participação" (SILVA; PASUCH; SILVA, 2012, p. 221).

Nossa pesquisa nos levou a refletir sobre a importância de reconhecer as culturas familiares e de construir estratégias de participação e comunicação entre família e escola, que precisam ser traduzidas em ações concretas, como: visitas, promoção de encontros e materiais comunicativos, incluindo as redes sociais. Também é preciso construir oportunidades de acolhimento e estimular a presença da família na escola, através de conselhos, bem como no cotidiano, estabelecendo-se um local de encontro para trocas, como, por exemplo, um mural informativo, uma sala aconchegante para receber as famílias, enfim, é necessário criar possibilidades e convites para integrar crianças, famílias e comunidade no contexto da escola.

Com relação à infraestrutura das escolas pesquisadas, cumpre esclarecer que ambas eram caricaturas das escolas urbanas e de Ensino Fundamental, com muros e portões fechados, janelas altas, grandes quantidades de mesas e cadeiras, uma estética que não traduzia a experiência do contexto, com imagens estereotipadas de animais, crianças e da natureza. A organização do dia a dia das crianças acontecia, na maior parte do tempo, em sala de aula, além de a disposição dos brinquedos e materiais não ter como eixo as interações e brincadeiras, como preconizam as DCNEI (BRASIL, 2009). Nesse sentido, é preciso pensar a 
especificidade da criança do campo na organização dos espaços, dos materiais, dos brinquedos e dos agrupamentos.

Estudiosas do tema, Pasuch, Silva e Silva (2012) tratam sobre a ambiência das aprendizagens significativas e das experiências da Educação Infantil do Campo, salientando três elementos importantes, qual sejam: a importância do movimento para o desenvolvimento da criança; a relação com a vida concreta; e o acesso aos recursos naturais disponíveis.

Os elementos apontados são significativos, pois vão ao encontro das possibilidades com que nos deparamos nas escolas da pesquisa: crianças potentes, com desejo de exploração e expressão, contando muitas histórias sobre o cotidiano vivido com suas famílias e comunidades, das quais emergem diferentes temas de pesquisa, de construção de conhecimentos e de brincadeiras. A escola possui um espaço externo rico em materiais naturais, como plantas, areia, árvores, terra, animais, entre outros elementos que se apresentavam de acordo com o ciclo da natureza, elementos próprios do contexto da vida do campo que precisam ser considerados nas práticas cotidianas da escola. Enfim, a potência do contexto de produção de vida das crianças do campo precisa estar articulada com o cotidiano da escola.

Consideramos que as questões apresentadas a partir de nossa experiência de pesquisa evidenciam ações fundamentais para pensar e orientar as propostas político-pedagógicas para a Educação no/do Campo. A pesquisa apresenta os sujeitos, suas demandas, seus desejos e suas necessidades emergentes. Cabe a nós, nesse coletivo, tecer essa grande rede para a construção da tão sonhada 'Política de Educação Infantil do Campo'. Porém, para além de um sonho, ela já foi constituída com fundamentos, princípios e estratégias, por meio da produção acadêmica na área, bem como do trabalho desenvolvido pelo GTI 'Educação Infantil do Campo: proposta para a expansão da política'.

Assim, quando olhamos um retrato, lembramos do passado, enxergamo-nos e pensamos no que será do futuro. Os dados da pesquisa apresentados neste artigo podem ser considerados como um retrato singular do contexto da Educação Infantil do Campo. Entretanto esse retrato nos permite afirmar que a oferta de Educação Infantil no campo para as crianças do campo já se encontra reconhecida no plano legal e possui documentos e estudos importantes para orientar a sua implementação.

Nesse momento histórico, a Educação Infantil do Campo precisa ser legitimada pelo poder público no plano real, respeitando as demandas das famílias e dos movimentos sociais e sindicais, na contramão da roda que gira em torno das desigualdades sociais e econômicas que envolvem os sujeitos do campo. Paulo Freire (1997) nos diria que, nesse contexto histórico, 
precisamos "esperançar", isto é, precisamos viver esse tempo com esperança. Não é possível esperar, pois as crianças não esperam: seu futuro é o hoje, o agora.

\section{Algumas considerações finais}

O presente artigo, ao apresentar uma síntese dos direitos garantidos em diferentes documentos legais às crianças pequenas residentes em áreas rurais, objetivou salientar que, embora recente, a Educação do Campo, nos últimos anos, teve um impulso legal bastante importante e necessário. Todavia, se temos um passado recente potente, o presente é complexo, devido às incertezas decorrentes da movimentação política, que, no atual momento, vem fazendo uma série de cortes nos investimentos em educação - fundamentais para que seja garantida a todas as crianças a vivência concreta de seus direitos.

Os dados apresentados buscaram elucidar a “[...] enorme dívida do poder público em relação aos direitos dos povos do campo à educação" (BRASIL, 2012, p. 4). Nessa perspectiva, destacamos o quanto ainda é longo e urgente o caminho a ser trilhado para minimizar as discrepâncias no que tange à oferta de vagas para a Educação Infantil entre os contextos urbano e rural brasileiros.

No que se refere especificamente à pesquisa Caracterização do atendimento de crianças de 0 a 6 anos residentes em áreas rurais do Estado do Rio Grande do Sul/Brasil (UFRGS, 2015), a partir do diálogo estabelecido com crianças, famílias, movimentos sociais e docentes das escolas nos dois contextos em que realizamos imersões, é possível assinalar que a oferta de vagas para as crianças pequenas do campo oportuniza também a emancipação das mulheres do campo para o trabalho, a ampliação da renda da família e, principalmente, o reconhecimento da escolarização como uma oportunidade fundamental por parte das comunidades, para que tenham melhores condições de vida.

No entanto as práticas vividas no cotidiano da escola requerem qualidade, ressalvado às crianças e às suas famílias o direito de terem suas identidades reconhecidas e valorizadas nesse contexto. Para tanto, a pesquisa evidenciou que a formação continuada dos professores e a elaboração da Proposta Político-Pedagógica são elementos essenciais e indispensáveis na busca por uma Educação Infantil no/do Campo de qualidade.

Neste artigo, apresentamos o nosso retrato sobre Educação Infantil do Campo a partir de nossas experiências como pesquisadoras e professoras imersas no contexto das práticas cotidianas e das políticas de Educação Infantil. Tivemos a intenção de provocar um debate para olhar a complexidade da relação que envolve o passado, o presente e o futuro da educação das crianças pequenas que vivem no campo. 


\footnotetext{
Notas

${ }^{1}$ Em função do processo de impeachment da Presidenta Dilma Rousseff, ocorrido em agosto de 2016, houve a posse do vice-presidente Michel Temer, com alterações na estruturação e composição do Ministério da Educação, bem como de todos os projetos e políticas sociais e educacionais, em especial aquelas vinculadas à Secadi, que foram, em sua maioria, extintas.

2 A Ação 2 - Estudo quantitativo de dados secundários esteve sob responsabilidade da professora Elsa Mundstock (UFRGS) e teve como fonte dados o IBGE e o INEP, ambos do ano de 2010.

${ }^{3}$ Os dados do Laboratório de Dados Estatísticos da UFPR e do Simec não foram apresentados no V Seminário Nacional de Educação Infantil do Campo, uma vez que ainda não estavam disponibilizados. Naquele período, nossa única fonte era a Ação 2 da Pesquisa Nacional.

${ }^{4}$ Nas etapas da creche e da pré-escola parcial rural de Santa Catarina, identificamos a redução de número de matrículas entre os anos analisados. No entanto observamos que, no que se refere à creche e à pré-escola integral rural, este estado teve aumento percentual de 57\%. O estado do Paraná foi o único a diminuir a oferta de Educação Infantil rural em tempo integral, mas aumentou em $95 \%$ a oferta de pré-escola parcial rural no período entre 2010 e 2016.

${ }^{5} \mathrm{O}$ novo governo apontado pelas autoras se referia ao governo de Michel Temer.
}

\section{Referências}

ALBUQUERQUE, Simone Santos de; FELIPE, Jane; CORSO, Luciana Vellinho. Apresentação. In: ALBUQUERQUE, Simone Santos de; FELIPE, Jane; CORSO, Luciana Vellinho (org.). Para pensar a Educação Infantil em tempos de retrocessos: lutamos pela Educação Infantil. Porto Alegre: Evangraf, 2017. p. 8-11.

ARENDT, Hannah. A crise na educação: entre o passado e o futuro. 7. ed. São Paulo: Perspectiva, 2011. v. 1.

BARBOSA, Maria Carmen Silveira et al. (org.). Oferta e demanda de Educação Infantil no Campo. Porto Alegre: Evangraf, 2012. v. 1.

BOITO, Crisliane. Práticas pedagógicas para infâncias no/do campo: experiências de uma escola em interlocução com crianças e famílias. 2017. 183 f. Dissertação (Mestrado em Educação) Universidade Federal do Rio Grande do Sul, Porto Alegre, 2017.

BRANDÃO, Carlos Rodrigues. Prefácio: Perguntas, pesquisas. Para quem? Para quê? In: OLIVEIRA, Maria Waldenez de; SOUSA, Fabiana Rodrigues de (org.). Processos educativos em práticas sociais: pesquisas em educação. 1 ed. São Carlos: Edufscar, 2014. p. 7-10.

BRASIL. Ministério da Educação. Secretaria da Educação Básica. Coordenação Geral de Educação Infantil. Critérios para um atendimento em creches que respeite os direitos fundamentais das crianças. Brasília, 1995.

BRASIL. Ministério da Educação. Conselho Nacional de Educação. Câmara de Educação Básica. Resolução $\mathrm{n}^{\circ}$ 1, de 3 de abril de 2002. Institui Diretrizes Operacionais para a Educação Básica nas Escolas do Campo. Diário Oficial da União: Brasília, DF, Seção 1, p. 32, 9 abr. 2002. Disponível em: https://bit.ly/2DdgUoZ. Acessado em: 5 out. 2016.

BRASIL. Ministério da Educação. Secretaria de Educação Básica. Política Nacional de Educação Infantil: pelo direito das crianças de zero a seis anos à Educação. [S. l.: s. n.], 2006.

BRASIL. Conselho Nacional de Educação. Câmara de Educação Básica. Resolução $n^{0}$ 2, de 28 de abril de 2008. Estabelece diretrizes complementares, normas e princípios para o desenvolvimento de 
políticas públicas de atendimento da Educação Básica do Campo. Diário Oficial da União: Brasília, DF, Seção 1, p. 81, 29 abr. 2008. Disponível em: https://bit.ly/2D9BQgr. Acesso em: 11 nov. 2017.

BRASIL. Ministério da Educação. Conselho Nacional de Educação. Câmara de Educação Básica. Resolução $\mathrm{n}^{\circ}$ 5, de 17 de dezembro de 2009. Fixa as Diretrizes Curriculares Nacionais para a Educação Infantil. Diário Oficial da União: Brasília, DF, Seção 1, p. 18, 18 set. 2009a. Disponível em: https://bit.ly/33k6n69 . Acesso em: 5 jul. 2014.

BRASIL. Ministério da Educação. Indicadores da Qualidade na Educação Infantil. Brasília, MEC/SEB/Coedi, 2009b.

BRASIL. Censo Escolar 2010. Brasília: MEC/Inep, 2010. Disponível em: https://bit.ly/2OGr7zs. Acesso em: 26 set. 2017.

BRASIL. Ministério da Educação. Secretaria de Educação Continuada, Alfabetização e Diversidade e Inclusão (SECADI). Educação do Campo: marcos normativos. Brasília: Secadi, 2012. Disponível em: https://bit.ly/2RBjv4y. Acesso em: 20 set. 2018.

BRASIL. Lei $\mathrm{n}^{\circ}$ 12.796, de 4 de abril de 2013. Altera a Lei ${ }^{\circ}$ 9.394, de 20 de dezembro de 1996, que estabelece as diretrizes e bases da educação nacional, para dispor sobre a formação dos profissionais da educação e dar outras providências. Diário Oficial da União: Brasília, DF, Seção 1, p. 1, 5 abr. 2013a. disponível em: https://bit.ly/3461ZYK. Acesso em: 20 set. 2018.

BRASIL. O Pronacampo. Pronacampo, [S. l.], 2013b. Disponível em: https://bit.ly/2pJLSSn. Acesso em: 25 set. 2017.

BRASIL. Grupo de Trabalho Interinstitucional. Educação Infantil do campo: proposta para a expansão de política. Brasília: MEC, mar. 2014. Disponível em: https://bit.ly/2XGhbKt. Acesso em: 25 set. 2017.

BRASIL. Sistema Integrado de Monitoramento e controle - SIMEC. Banco de dados. Consulta em agosto de 2017. Disponível em: https://bit.ly/2qEGiBi. Acesso em: 20 ago. 2017.

BRASIL. Parâmetros Nacionais de Qualidade da Educação Infantil. Brasília: MEC/SEB/Coedi, 2018. Disponível: https://bit.ly/2qEF0Gs. Acesso em: 14 ago. 2019.

BRASIL. Ministério da Educação. Secretaria de Educação Básica. Diretoria de Currículos e Educação Integral. Coordenação Geral de Educação Infantil; UNIVERSIDADE FEDERAL DO RIO GRANDE DO SUL. Faculdade de Educação. Pesquisa Nacional Caracterização das práticas educativas com crianças de 0 a 6 anos de idade residentes em área rural - 2012. Relatório Ação 2: Análise dos dados quantitativos das condições educacionais de crianças de 0 a 6 anos de idade residentes em área rural. v. 1. [S. l.]: MEC, 2012a. Disponível em: https://bit.ly/2OGrVV0. Acesso em: 12 ago. 2017.

BRASIL. Ministério da Educação. Secretaria de Educação Básica. Diretoria de Currículos e Educação Integral. Coordenação Geral de Educação Infantil; UNIVERSIDADE FEDERAL DO RIO GRANDE DO SUL. Faculdade de Educação. Pesquisa Nacional Caracterização das práticas educativas com crianças de 0 a 6 anos de idade residentes em área rural - 2012. Produção acadêmica nacional sobre a Educação das crianças residentes em área rural (1996-2011). [S. l.]: MEC, 2012b. Disponível em: https://bit.ly/37yX1Xe. Acesso em: 22 ago. 2019.

CALDART, Roseli Salete. Sobre Educação do campo. In: SANTOS, Clarice Aparecida dos (org.). Educação do Campo: Campo - políticas públicas - educação. Brasília: Nead especial, 2008. p. 67-86.

CALDART, Roseli Salete et al. (org.) Dicionário da Educação do Campo. São Paulo: Expressão Popular, 2012. 
FLORES, Maria Luiza Rodrigues; ALBUQUERQUE, Simone Santos de. Direito à Educação Infantil no contexto da obrigatoriedade da matrícula escolar na pré-escola. Textura, Canoas, v. 18, n. 36, p. 87-110, jan./abr. 2016. Disponível em: https://bit.ly/33dKbKE. Acesso em: 20 set. 2018.

FREIRE, Paulo. Pedagogia da Esperança: um reencontro com a Pedagogia do Oprimido. Rio de Janeiro: Paz e Terra, 1997.

INSTITUTO BRASILEIRO DE GEOGRAFIA E ESTATÍSTICA - IBGE. Estatística de gênero: uma análise do Censo Demográfico 2010. Rio de Janeiro, 2014. Disponível em: https://bit.ly/2KNJWQd. Acesso em: 25 set. 2017.

MOSS, Peter. Para além do problema com qualidade. In: MACHADO, Maria Lúcia de A. (org.). Encontros e desencontros em educação infantil. São Paulo: Cortez, 2002. p. 17-25.

RIO GRANDE DO SUL. Tribunal de Contas do Estado. Radiografia da Educação Infantil no RS: análise do desempenho 2015. Porto Alegre, dez. 2016. Disponível em: https://bit.ly/2OCr5IZ. Acesso em: 25 set. 2017.

ROSEMBERG, Fúlvia. A criança pequena e o direito à creche no contexto dos debates sobre infância e relações raciais. In: BENTO, Maria Aparecida Silva (org.). Educação Infantil, igualdade racial e diversidade: aspectos políticos, jurídicos e conceituais. São Paulo: CEERT, 2011. p. 11-46.

ROSEMBERG, Fúlvia; ARTES, Amélia. O rural e o urbano na oferta de educação para crianças de até 6 anos. In: BARBOSA, Maria Carmen Silveira et al. (org.). Oferta e demanda de Educação Infantil no Campo. Porto Alegre: Evangraf, 2012. p. 15-69.

SILVA, Ana Paula Soares da e; PASUCH, Jaqueline. Orientações Curriculares para a Educação Infantil do Campo. [S. l.: s. n.], 2010. Disponível em: https://bit.ly/2OgG9gp. Acesso em: 6 set. 2017.

SILVA, Ana Paula Soares da e; PASUCH, Jaqueline; SILVA, Juliana Bezzon. Educação Infantil do Campo. São Paulo: Cortez, 2012.

SILVA, Isabel de Oliveira; SILVA, Ana Paula Soares; MARTINS, Aracy Alves (org.). Infâncias do campo. Belo Horizonte: Autêntica Editora, 2013.

UNIVERSIDADE FEDERAL DO PARANÁ. Laboratório de Dados Educacionais. Disponível em: https://dadoseducacionais.c3sl.ufpr.br/\#/. Acesso em: 12 out. 2017.

UNIVERSIDADE FEDERAL DO RIO GRANDE SUL. Faculdade de Educação. Projeto de Assessoramento Técnico-Pedagógico na implementação do Proinfância a um grupo de Municípios do Estado do Rio Grande do Sul. Relatório Técnico Geral. Porto Alegre: MEC/SEB//UFRGS, jan. 2014. (Não publicado).

UNIVERSIDADE FEDERAL DO RIO GRANDE SUL. Faculdade de Educação. Departamento de Estudos Especializados. Grupo de Estudos sobre Educação Infantil. Pró-Reitoria de Pesquisa. Caracterização do atendimento de crianças de 0 a 6 anos residentes em áreas rurais do Estado do Rio Grande do Sul/Brasil. Relatório de Pesquisa de Iniciação Científica. Porto Alegre: UFRGS, abr. 2015. Disponível em: https://bit.ly/2P48wyH. Acesso em: 20 ago. 2018 